\title{
Pütürge Metamorfitlerindeki Amfibolit Fasiyesi Granatların Mineralojisi ve Sm-Nd İzotop Jeokimyası
}

\author{
Hilal KAYA ${ }^{1}$, Ayşe Didem KILIÇ ${ }^{* 2}$ \\ ${ }^{1}$ Elazığ Belediyesi, Jeoloji Yüksek Mühendisi, Elazığ, Türkiye \\ ${ }^{2}$ Fırat Üniversitesi, Jeoloji Mühendisliği Bölümü, Elazığ, Türkiye \\ Geliş / Received: 02/04/2018, Kabul / Accepted: 02/08/2018
}

\begin{abstract}
$\ddot{O} z$
Toros Orojenik kuşağı üzerinde, Malatya-Pütürge ilçesindeki metamorfitlere ait granatlar, granat mikaşistler ve granat stavrolit/silimanit mika şistler içerisinden seçilmiştir. Elektro-mikropirob verilerinden (EPMA) Alm81Prp8Grs7Spess5 bileşimli olduğu belirlenen bu granatların türü, almandin'dir. Almandin türü bu granatlarda, kısmen bazı tanelerinde ters zonlanma belirlenmiştir. Bu zonlanmanın varlığı ve granatı çevreleyen silimanit ve biyotitler; katyon alış-veriş reaksiyonlarının granat kimyası üzerinde belirleyici olduğunu işaret eder. Kayaçların mineral parajenezlerinden ve granat-biyotit jeotermometresi hesaplamalarından elde edilen sonuçlardan, metamorfizma sıcaklığının $600^{\circ} \mathrm{C}$ aştığı ve metamorfik masifin bölgesel tektonikten etkilenmesi nedeniyle de basınç gölgesi, kapanımların yönlenmesi, belirgin şistozite ve ötelenmiş foliasyon gibi yapılarının geliştiği görülmüştür. Metamorfitler, amfibolit fasiyesinde ilerleyen ve yeşilşist fasiyesinde gerilen metamorfizma gösterirken, metamorfizmada bölgenin aktif tektoniğinin önemli etkisi vardır. Bunun önemli işaretlerinden biri, granatın çekirdeği ve kenarından alınan Sm-Nd mineral yaş verisi $(81.53 \pm 0.10$ ve $82.18 \pm 0.17)$ arasındaki farkın azlığıdır. Bu özellik, aynı zamanda masifin ani yükselmesi sonucunda gelişen soğumanın mineraller üzerindeki etkisinin de kanıtıdır.
\end{abstract}

Anahtar Kelimeler: Gd-Türkiye, Sintektonik, Neotetis, Pütürge, Zonlanma

\section{Petrochemistry of Amphibolite Garnets in The Pütürge Metamorphites and Sm-Nd İsotope Geochemistry}

\begin{abstract}
The metamorphite in Malatya-Pütürge vilage on Tauride orogenic belt has been studied in garnets. The garnets selected from garnet-mica schistes, staurolite/sillimanite mica schistes and its electronmicropirobe (EPMA) analysed shows as almandine with Alm81Prp8Grs7Spess5 composition. In some garnets has been determined reverse zoning. The zoning, sillimanite and biotite mantling garnet show that by effect on garnets of cation echange reactions. Data from mineral paragenesis of rocks and garnet-biotite geothermometer, metamorphism heat is $>600^{\circ} \mathrm{C}$. Furthermore, metamorphic rocks effects from regional tectonics which are pressure fringes, inclusion orientations, schistosite and iterated foliation. In the prograde and retrograde metamorphism in amphibolite facies play a role active tectonic of region. Likewise, Sm-Nd mineral age data of garnets (rim to core) $81.53 \pm 0.10$ and $82.18 \pm 0.17$ shows mineral cooling as a results of suddenly exhumation time of massif.
\end{abstract}

Keywords: Se-Turkey, Syntectonic, Neotethyan, Pütürge, Zoning

\section{Giriş}

Pütürge Metamorfitleri, Üst Kretase'den itibaren Avrasya ve Arap-Afrika levhalarının birbirleriyle çarpışması sonucu oluşmuş, yüzlerce kilometre karelik alanda yayılım sunan (Perinçek ve Özkaya 1981; Şengör ve Y1lmaz, 1981; Robertson ve Dixon, 1984), Torid-Anatolid platformu ile kenar kıvrımları içinde yer alan en büyük masiftir (Ketin, 1966) (Şekil 1). Pütürge Metamorfitleri
Bitlis Masifi'nin batıdaki devamı olarak kabul edilir ve 'Pütürge-Bitlis Sütur zonu' adı altında kullanılır. Pütürge-Bitlis Sütur zonu boyunca yayılım gösteren birim; Pelit/metapelit, metapisamit, metagranit, amfibolşist, mermer ve kuvarsitten oluşan kayaç çeşitliliği sunar. Mineral parajenezleri masifin amfibolit fasiyesinde ilerleyen (prograd) ve yeşilşist fasiyesinde gerileyen (retrograd) iki tür metamorfizma geçirmiş 
olduğunun işaretidir. Granatların da içinde yer aldığı metapelit ve kismen metapsamitlerin diğer yaygın mineralleri ise muskovit, biyotit ve alüminyum silikat mineralleridir. Magmatik ve metamorfik birçok kayaç türünde görülebilen granat, plajiyoklaz ve zirkon mineralleri gibi zonlanma özelliği gösterebilir. Granat mineralinin zonlanması, genellikle ortamın basınç-sıcaklık koșulları, metamorfizma geçmişi, metamorfik reaksiyonlar ve tektonizma hakkında bilgi veren önemli bir kaynaktır (Yardley, 1977; Spear ve Selverstone, 1983; Kohn vd., 1997; Kılıç ve Ateş, 2015). Granatlarda zonlanmanın oluşumu üzerine genel olarak, üç model önerilmiştir: $\mathrm{Bu}$ modellerden ilki, Hollister (1966) ve Atherton (1968) tarafindan önerilen izotermal fraksiyonlaşma modeli, bir diğeri Lasaga vd. (1977) tarafindan ifade edilen kristalin büyümesi sırasında veya sonrasinda meydana gelen kimyasal diffüzyon ve katyon alış-verişi reaksiyonları modeli, son model ise Miyashiro ve Shido (1973) ve Tracy vd. (1976)'nın belirttikleri, ilerleyen veya gerileyen metamorfizma sırasındaki büyümeye bağlı zonlanma modelleridir. Belirtilen tüm bu modellerin biri, birkaçı veya hepsi zonlanmanın gelişiminde etkili olabilir (Cygan ve Lasaga, 1982). Granatlarda; normal zonlanma, manganca zengin kenara sahip normal zonlanma ve ters zonlanma olarak üç tip zonlanma mevcuttur. Normal zonlanma; kristalin çekirdeğinden kenarına doğru Mn ve $\mathrm{Ca}$ içeriğinin azalıp, $\mathrm{Fe}$ ve $\mathrm{Mg}$ içeriğinin arttığı zonlanmadır. Mn içeriği çekirdeğe nazaran kenarda artış gösteriyorsa, ikinci tip zonlanmadan bahsedilir. Kristalin çekirdeğinden kenarına doğru Fe içeriği artar veya azalır, bu oranda $\mathrm{Mn}$ içeriği de artarsa ters zonlanma adını alır (Ruiz, 1976).Zonlanma göstersin veya göstermesin metamorfik kayaçlardaki granatlar; kristalinin büyümesi, büyüme oranı, büyüme zamanı ve metamorfizma yaşını belirlemek için $\mathrm{Lu}-\mathrm{Hf}$ veya $\mathrm{Sm}-\mathrm{Nd}$ izotoplarında önemli bir mineraldir (Christensen vd.,1989). Lu-Hf izotopu erken kristalizasyon yaşını verirken, Sm-Nd izotop verisi ise geç kristalizasyon yaşını verir. Bu çalışmada, amfibolit fasiyesi koşullarında oluşmuş ve metapelit/metapsamit kayaçları içerisinde yaygın olarak görülen granatların, bileşimi, zonlanmanın oluşumuna sebep olan prosesler ve granatların $\mathrm{Sm}-\mathrm{Nd}$ mineral yaş tayininden, metamorfizma yaşının belirlenmesi konuları amaçlanmıştır.

\section{Materyal ve Metot}

Litolojik özellikleri yukarıda açıklanan ve granatl 1 mikaşistlerden seçilen granat örneklerinin, ince kesitlerinin hazırlanması Fırat Üniversitesi Jeoloji Mühendisliği Laboratuvarı'nda, Granatların Sm-Nd mineral yaş analizi TIMS yöntemiyle ACTLAB(Kanada)'da, Elektron mikroprob analizi (EPMA) ise Orta Doğu Teknik Üniversitesi Merkez Laboratuvarı'nda yapılmıştır. TIMS yöntemiyle Sm-Nd mineral yaş tayininde, minerallerin seçimi ve element çıkarma işlemleri mevcuttur. Minerallerin ayıklanması, çeneli kırıcı, silindirik kırıcı, manyetik ayırıcı ve binoküler mikroskopta elle ayırma aşamaları tamamlanmış ve belirlenen granat örnekleri ACTLAB'a gönderilmiştir. Elektronmikropirob analizlerde JEOL marka JXA8230 model EPMA aleti kullanılmış olup, çalışma koşulları olarak 15 kV'lik artan voltaj, $15 \mathrm{nA}$ akım ve $5 \mu$ m'lik 1şın çap1 uygulanmıştır. Toplam 25 örnekten özenle seçilen granatlara 10 noktadan kantitatif, 4 granat mineralden çizgi profili elde edilmiştir.

\section{Bulgular}

\subsection{Jeoloji}

Alpin orojenik kuşağında ve Neotetisin güney kolu üzerindeki Doğu Anadolu'da, sedimanter, magmatik ve metamorfik kayaçların çeşitliliği mevcuttur. Güneydoğu Anadolu kuşağı boyunca yüzeylenen; Malatya, Keban ve Bitlis masifi'nden sonraki 


\begin{abstract}
en büyük masif olan Pütürge metamorfik foliasyonunun belirgin olarak ortaya masifi, ortalama $400 \mathrm{~km}$ uzunluk ve $70 \mathrm{~km}$ çıkmasına sebep olmuştur. Bunlardan genişliğe sahiptir. Üst Kretase'den itibaren birincisi, şistozite ve gnays bandlaşması Avrasya ve Arap/Afrika levhalarının şeklinde gelişmiştir. İkincisi ise, sleyt klivajı birbirlerine yaklaşması ve çarpışmalarının şeklinde gelişmiştir. Ayrıca, makaslama sonucu oluşan metamorfik masif ve zonlarında, milonitik foliasyon, kayaçlarda çevresinde tektonizma etkindir (Hall 1976; kırılma ve yer yer ufalanma yaygındır. Şengör ve Y1lmaz 1981; Michard vd., 1984; Pütürge metamorfitleri; Gözlü gnays, granitik Robertson ve Dixon 1984; Ricoue vd., 1984; gnays, amfibolşist, kalkşist ve mermer Yazgan ve Chessex 1991). Bölgede özellikle hem eğim-atımlı ters hem de doğrultu-atımlı fayların oluşturduğu tektonik yapı, Pütürge metamorfik masifinin artan kalınlığına neden olmuştur. Foliasyon ve şistozite arabantlı şistleri kapsar (Şekil 1). Granatların yaygın olarak gözlendiği kayaç grupları ise; Granat-mikaşist, granat-stavrolit mikaşist, granat-silimanit mikaşist ve granat-biyotit gnays'tır.
\end{abstract} tektonizmadan etkilenmiș ve en az iki farklı

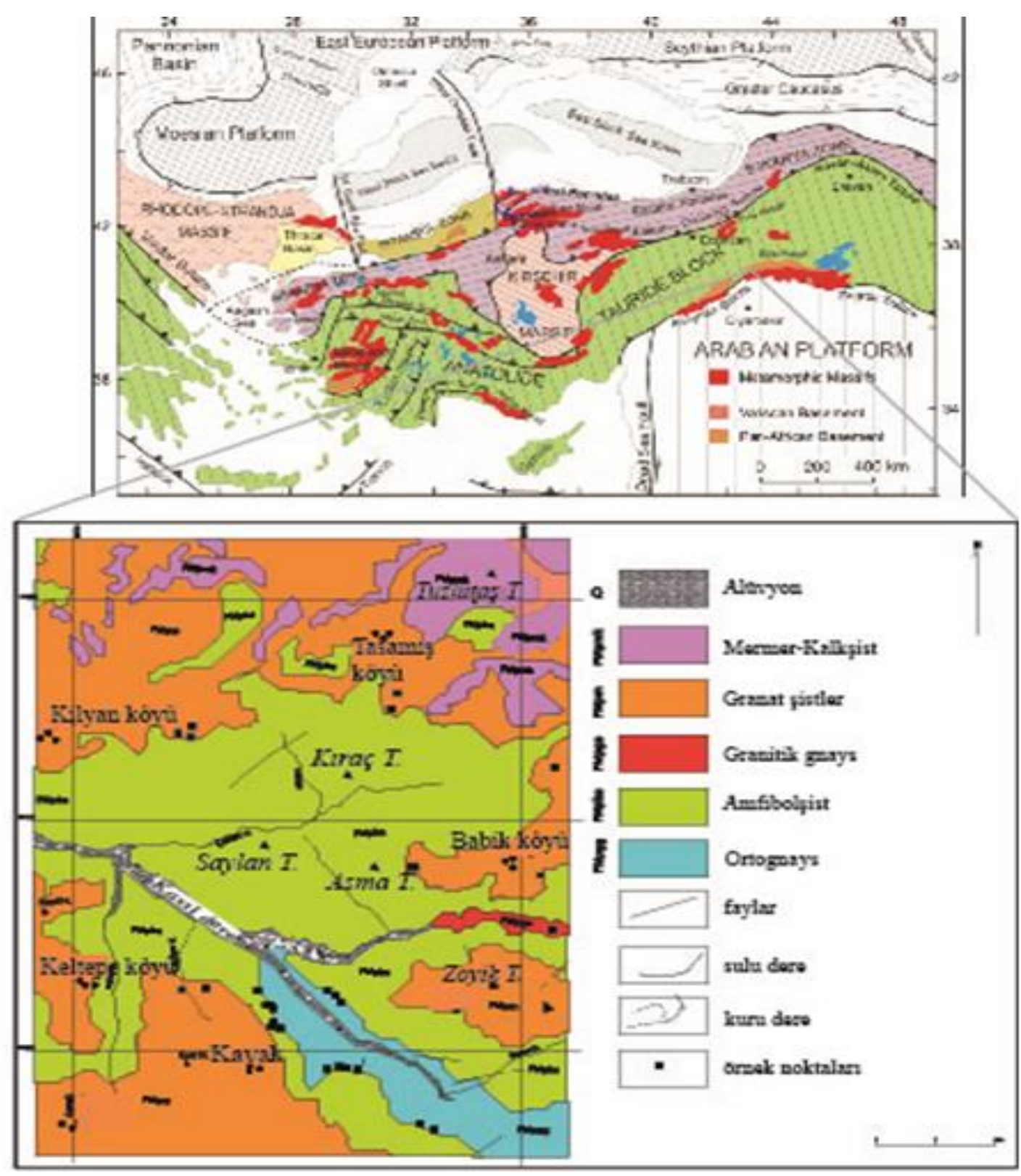

Şekil 1. Türkiye'deki metamorfik masiflerin dağılımı (Roland vd., 2011) ve inceleme alanının jeolojik haritası (Kılıç ve Ateş, 2015). 


\subsection{Petrografi}

Mineralojik incelemede, pelitik, yer yer psamitik ve kalksilikat özellikte olduğu belirlenen ve petrografik adlaması granatmika şist, orto/para gnays, amfibol şist, kalkşist ve mermer şeklinde yapılan Pütürge metamorfik kayaçları bölgesel metamorfizmanın tüm özelliklerini taşımaktadır. İnceleme konusu kayaçların mikroskobik incelemeleri dokularının genellikle; Lepidoblastik, lepidogranoblastik, lepido-porfiro/poikiloblastik olduğu gösterir. Lepido porfiroblastik/ poikiloblastik dokudaki granatlı mikaşistlere ait granatlar, $0.5 \mathrm{~mm}-1.5 \mathrm{~cm}$ arasinda değişen tane boyuna sahiptir (Şekil 2). Bu kayaçlarda granatın yanında feldispat, kuvars, muskovit, biyotit, silimanit/stavrolit ve klorit mineralleri bulunur (Şekil 2a, b,c,d). Alüminyum silikat mineralleri yaygın olmasına rağmen aynı kayaç içerisinde bir arada görülmez (Şekil 2d). Genellikle, silimanitin bulunduğu kesitte stavrolit veya disten bulunmaz. Bunun sebebi, metamorfik derecenin artmasıyla, stavrolitin bozulması ve silimanitin gelişmesidir. Granatlar, genellikle yarı özşekilli, kısmen özşekilli, iri kristaller halinde, bazı kesitlerde ise küçük taneler şeklindedir (Şekil 2). Bir kısım porfiroblastlarda basınç gölgesi (pressure fringes) tipiktir (Şekil 2b). Sin-tektonik metamorfizmanın bir işaret olan basınç gölgesinin görüldüğü granatlarda, muskovit, biyotit ve klorit mineralleri porfiroblastları çevrelemektedir. Ayrıca, granat porfiroblastlarının bir kısmı yuvarlağımsı görünürken, bazı granatların baskılanmış geometri sunması (Şekil 2c), etkin bir bölgesel şistoziteyi açığa çıkaran, sürekli deformasyonu işaret eder (Yardley, 1977). Granatlarda belirlenen kapanım mineralleri ilmenit, feldispat ve kuvars olup, bu tür granatlarda yer yer kırıklar da gelişmiştir (Şekil 2c,d). Mikaşistlerin genel mineral parajenezi, granat-silimanit-muskovit-biyotitkuvars-feldispat, granat-stavrolit-kuvarsmuskovite(klorit)-feldispat, granat-muskovitbiyotit-feldispat-kuvars- klorit şeklindedir (Şekil 2). Mikroskobik incelemelerde, granat ve biyotit minerallerinin klorite dönüşmesi, feldispat minerallerinin kaolenleşmesi, metamorfitlerinin gerileyen metamorfizmasına işaret ederken, granatın silimanite dönüşümü ilerleyen metamorfizmaya işaret eder (Erkan, 2013) (Şekil 2).
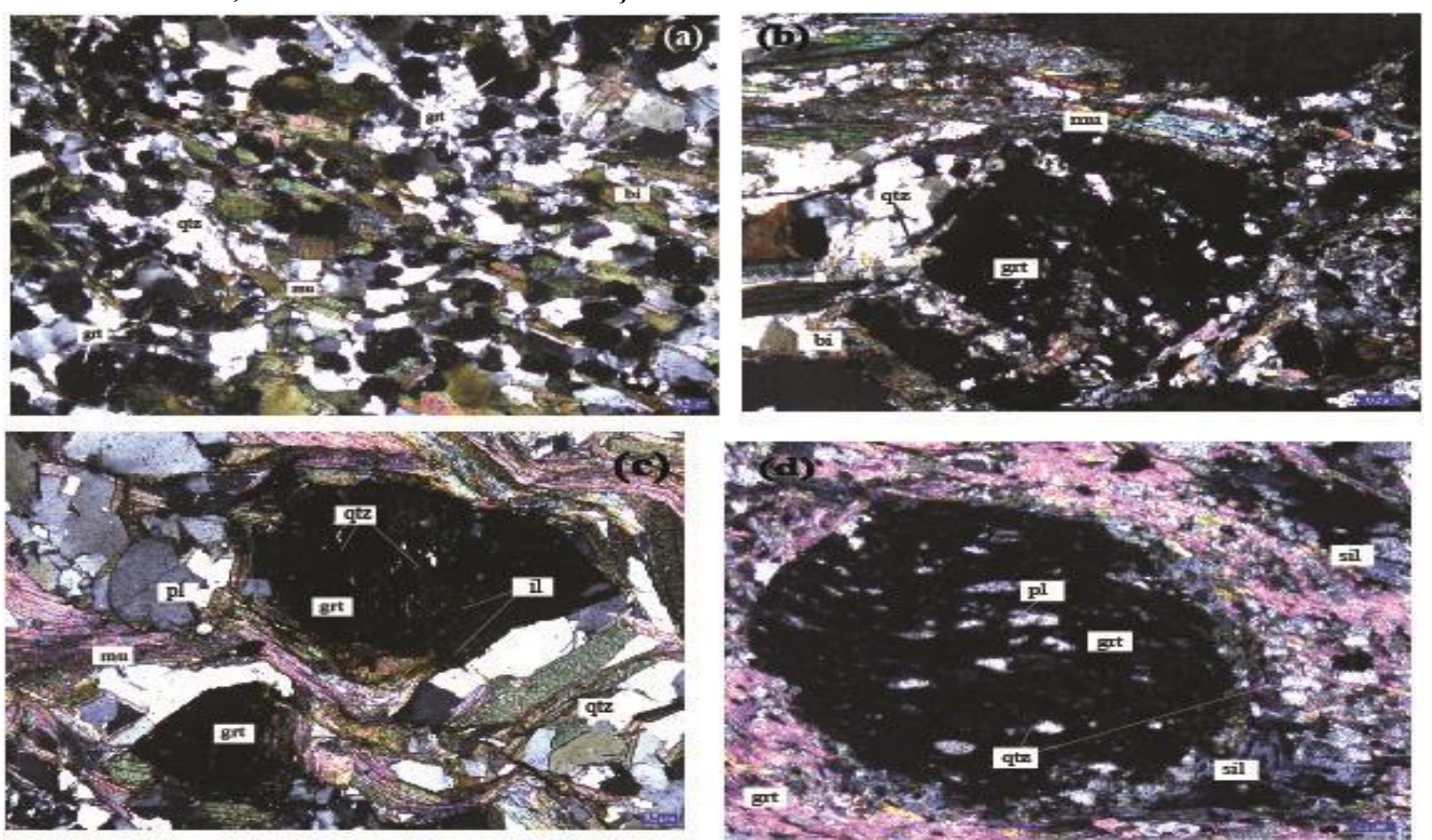

Şekil 2. Mika şistlerdeki granatların mikroskop görüntüleri. (a) Granat mika şistlerdeki küçük tane boyutuna sahip kapanım içermeyen granatlar, (b) Granat mika şistlerdeki kapanımlı granat porfiroblastları ve basınç gölgesi, (c) Baskılanmış granat kristali, (d) Silimanitle çevrelenmiş kapanım içeren granat porfiroblastları. 


\subsection{Jeokimya}

Petrografik incelemeleri yapilan ve mineral bileşimleri belirlenen Pütürge metamorfitlerine ait kayaçlar, arazinin bazı kesimlerde alterasyona ve yüzeysel ayrışmaya uğramıştır. Bu nedenle, kayaçların adlandırılmasında mineralojik ve kimyasal analizleri birlikte değerlendirilmiştir. Jeokimyasal analizlerde, kayaçların major oksit ve iz element verilerinden de bu metamorfitlerin köken kayacının magmatik, az bir kısmı killer ve karbonatlı killerden oluşan sedimanter kayaçlar olduğu (Kılıç ve Ateş, 2014) ve Pütürge metamorfitlerine ait magmatik kayaçların, bazik ve kıtasal kabuktan kirlenmiş kalkalkalen özellikte, şist ve gnayslarınsa kirlenmeden etkilenmemiş bir özellikte olduğu görülmüştür. $\mathrm{Bu}$ çalışmanın amacı doğrultusunda, petrografik özellikler ve tüm kayaç jeokimyasından ksaca bahsedilip, daha çok mineral kimyası ve mineral yaş tayini üzerinde durulacaktır.

\subsection{Granatların Mineral Kimyası}

Pütürge metamorfitinin metapelitlerinden seçilen granatlar, elektron-mikro pirob analizi (EPMA) ile incelenmiş ve analiz sonuçları Tablo 1' de verilmiştir. Tane boyutu $3 \mathrm{~mm}-1.2 \mathrm{~cm}$ arasında değişen toplam 25 granat tanesinden, kristal yapis1 bozulmamış ve kısmen çatlaksız olan dört örnek seçilmiştir. Granat kristalinin merkez ve kenarını kapsayacak şekilde on noktadan major oksit bileşimi belirlenmiş ve bileşim grafiklere aktarılmıştır (Şekil 3). Granatların EPMA analizlerinde, granat-mikaşistlerdeki küçük tane boyutuna sahip granatların $\mathrm{FeO}$ oranındaki değişim hariç, genelde daha homojen bir bileşim sergilediği görülür (Şekil 2, Şekil 3a). Bu granatların $\mathrm{X}_{\mathrm{Mg}}$ değeri, çekirdekte 0.070 kenar kısmında ise 0.051-0.055 kadardır. Mn, Mg, Ca-oksit oranları da benzer bir grafik sergilerken, $\mathrm{FeO}$ oranı kristalin bir kenarında ani düşüş gösterir. $\mathrm{Bu}$ örneğin mikroskobik incelemelerinde granatın bir kenarında biyotit minerali varlı̆̆ değişimin biyotitle granat arasında gelişen, katyon alış-verişi reaksiyonlarından kaynaklanabileceği (Crawford, 1977) ve benzer bir durum Granat-silimanit mika şistlerden alınan, iri kristalli $(1-1.2 \mathrm{~cm})$ ve çatlaklı granat örneğinde de var olduğu belirlenmiştir (Şekil 2, Şekil 3b). Bu örnekte, granatı çevreleyen silimanit minerali mevcuttur. Silimanitin granat porfiroblastını çevreliyor olması, $\mathrm{FeO}$ değişiminin çekirdeğe nazaran kristal kenarında daha düşük olmasına sebep olmuştur. Tracy vd., (1976), $\mathrm{Fe}$ ve kısmen Mn'daki bu değişimi fraksiyonlaşma mekanizması sonucu mineralin bileşimindeki elementlerin tükenmesi olarak açıklar. FeO grafiği Şekil 3c ve Şekil 3d granatlarındada düzensizlik göstermektedir. Zikzaklı bu grafik, granat porfiroblastları içerisindeki kapanım minerallerinin varlığına yorumlanmıştır. Zira bu granat kristalinin mikroskobik incelemesinde bol kapanım mineralleri görülür. Şekil 3c,d örneklerinin bir diğer özelliği ise, $\mathrm{MnO}$ 'in, $\mathrm{MgO}$ grafiğgine göre çekirdekten kenara doğru artışı, yani minimal bir artışın varlığıdır. Mn grafiğinin, granat çekirdeğinde kenara nazaran yüksekliği, granatı çevreleyen matrikste manganın tükenmesini işaret ederken, Mn içeriği yüksek minerallerin matrikste bulunmayışı da bunu doğrular. Carlson (1989) böyle bir prosesin matriks içerisinde küçük granat kümeleri oluşturacağını, metapelitlerdeki kısmen küçük granat taneleri (Şekil 2) ve granatların $\mathrm{CaO}, \mathrm{MgO}$, kısmen $\mathrm{MnO}$ bileşimi bakımından homojen bileşim göstermesi, granat oluşumunun $550-650^{\circ} \mathrm{C}$ sicakliklarda oluşabileceğini, yani Amfibolit fasiyesi koşullarını işaret ettiği belirtilir (Perchuk et al., 2007). Mikroskobik incelemelerde silimanitin var olması ise sıcaklığın biraz daha yüksek olup, amfibolit fasiyesinin üst koşullarının göstergesidir. Bazı kesitlerde, granatın stavrolitle çevrelenmiş olması ve düzgün kristal kenarlarının varlı̆̆ metamorfizmanın yüksek sicaklık koşulllarının diğer bir işaretidir (Şekil 2). Bu 


\begin{tabular}{|c|c|}
\hline 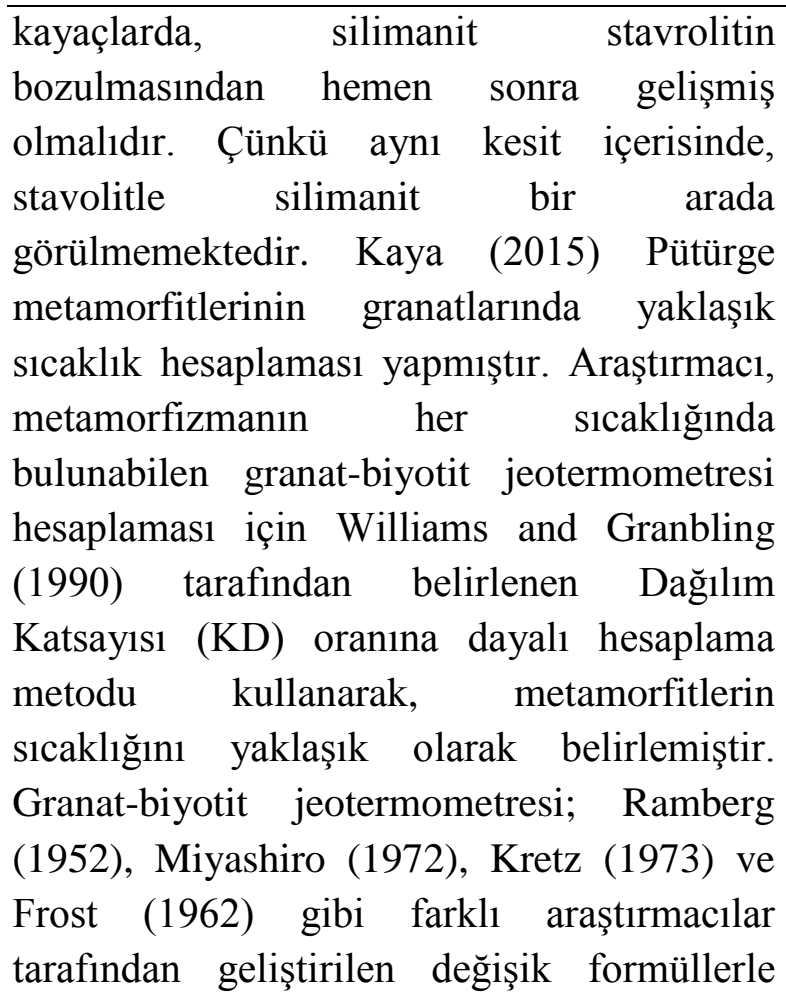 & $\begin{array}{l}\text { KatsayıSı }(\mathrm{KD}) \text { değerini, } \mathrm{Mg} / \mathrm{Fe}) \mathrm{gr} /(\mathrm{Mg} / \mathrm{Fe})_{\mathrm{bi}} \\
\text { veya }\left(\mathrm{X}_{\mathrm{FeBio}} \mathrm{X}_{\mathrm{Mggr}}\right) /\left(\mathrm{X}_{\mathrm{MgBio}} . \mathrm{X}_{\mathrm{Fegr}}\right) \text { formülleri } \\
\text { ile her bir mineral için ayrı ayrı hesaplamış } \\
\text { ve sonucunda, yaklaşı } 628^{\circ} \mathrm{C} \text { lik bir sıcaklık } \\
\text { belirlemiştir ki, bu sıcaklık stavrolit zonu } \\
\text { sıcaklığıdır (Kılıç ve Kaya, 2015). Granat } \\
\text { grafiğinde, MgO bileşimi düzgün dağılım } \\
\text { sergilese de, minimal değişimler mevcuttur. } \\
\text { Örneğin Şekil 3a,b'de merkezden kenara } \\
\text { doğru küçük bir azalma olması, retrograd } \\
\text { metamorfizmayı işaret ederken, Şekil 3c,d'de } \\
\text { merkezden kenara doğru MgO oranındaki } \\
\text { küçük artış prograd metamorfizmanın } \\
\text { göstergesidir. Mikroskobik incelemelerde } \\
\text { bazı granatların çevresinde, granatı } \\
\text { sarmalamış kloritler görülürken, diğer bazı } \\
\text { granatlarda silimanitle çevrelenmesi } \\
\text { kimyasal verileri doğrulamaktadır (Şekil 2). }\end{array}$ \\
\hline
\end{tabular}

hesaplanabilmektedir.

Araştırmac1

çalışmasında kullandığı, Williams and

Granbling (1990) granat-biyotit

jeotermometresi metodunda, granat ve granat

sınırındaki biyotit mineralinin Dağılım
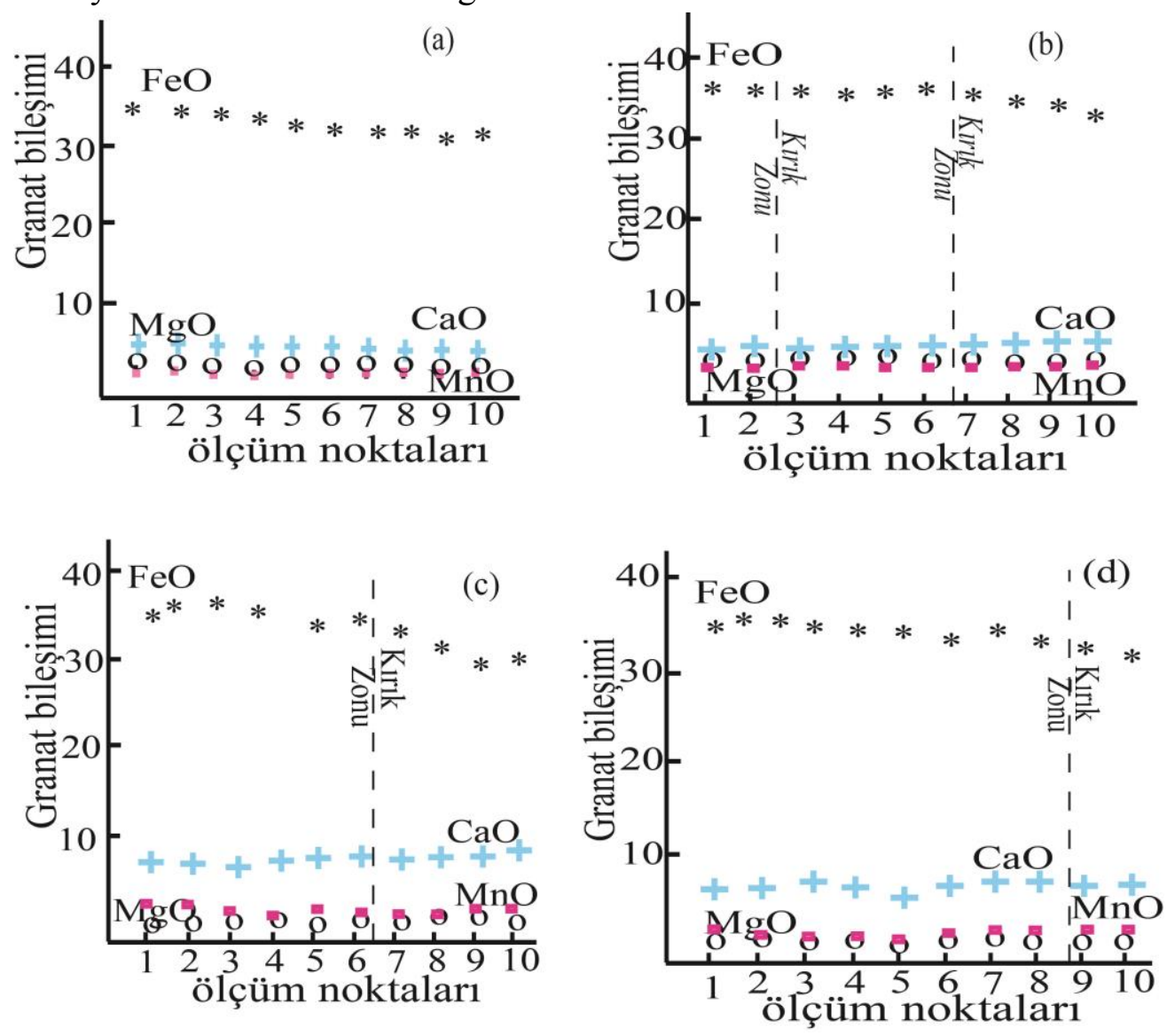

Şekil 3. Granatların elektronmikropirob analizine ait major-oksit profilleri. (a) Gr1 nolu granat örneği, (b) Gr2 nolu granat örneği, (c) Gr3 nolu granat örneği, (d) Gr4 nolu granat örneği. 
Tablo 1. Elektron mikropirob metoduyla granatların major oksit bileşimi.

\begin{tabular}{|c|c|c|c|c|c|c|c|c|c|c|c|c|c|}
\hline $\mathrm{Gr}_{1}$ & $\mathrm{SiO}_{2}$ & $\mathrm{TiO}_{3}$ & $\mathrm{Al}_{2} \mathrm{O}_{3}$ & $\mathrm{FeO}$ & $\mathrm{MgO}$ & $\mathrm{MnO}$ & $\mathrm{CaO}$ & $\mathrm{Na}_{2} \mathrm{O}$ & Total & $\mathrm{X}_{\mathrm{Fe}}$ & $\mathrm{X}_{\mathrm{Mg}}$ & $\mathrm{X}_{\mathrm{Ca}}$ & $\mathrm{X}_{\mathrm{Mn}}$ \\
\hline 1 & 36.46 & 0.20 & 21.96 & 32.91 & 2.91 & 3.11 & 2.02 & 0.03 & 99.13 & 0.81 & 0.055 & 0.058 & 0.076 \\
\hline 2 & 36.65 & 0.16 & 23.19 & 32.83 & 2.16 & 2.04 & 2.08 & - & 100.0 & 0.85 & 0.043 & 0.049 & 0.052 \\
\hline 3 & 35.76 & 0.12 & 22.61 & 32.90 & 2.32 & 2.17 & 2.79 & 0.03 & 99.61 & 0.83 & 0.045 & 0.064 & 0.054 \\
\hline 4 & 36.12 & 0.01 & 22.05 & 32.33 & 3.43 & 2.24 & 2.71 & 0.01 & 99.70 & 0.81 & 0.066 & 0.062 & 0.056 \\
\hline 5 & 35.94 & 0.01 & 22.71 & 31.50 & 3.53 & 2.10 & 2.07 & 0.03 & 98.09 & 0.82 & 0.070 & 0.054 & 0.054 \\
\hline 6 & 35.51 & - & 23.01 & 31.73 & 3.79 & 2.11 & 2.17 & 0.04 & 98.36 & 0.81 & 0.075 & 0.051 & 0.054 \\
\hline 7 & 36.68 & 0.04 & 22.79 & 30.93 & 3.91 & 2.10 & 2.72 & - & 99.17 & 0.80 & 0.078 & 0.032 & 0.054 \\
\hline 8 & 36.27 & 0.09 & 22.46 & 31.27 & 3.94 & 3.16 & 2.76 & - & 99.95 & 0.78 & 0.075 & 0.063 & 0.078 \\
\hline 9 & 37.68 & 0.07 & 22.34 & 29.48 & 3.98 & 2.13 & 2.40 & - & 99.98 & 0.79 & 0.083 & 0.059 & 0.057 \\
\hline 10 & 38.03 & 0.16 & 21.69 & 31.19 & 4.33 & 2.24 & 2.04 & - & 99.70 & 0.82 & 0.051 & 0.031 & 0.086 \\
\hline \multicolumn{14}{|l|}{$\mathrm{Gr}_{2}$} \\
\hline 1 & 37.70 & 0.25 & 21.29 & 31.94 & 2.53 & 3.28 & 1.31 & 0.13 & 98.43 & 0.83 & 0.050 & 0.031 & 0.086 \\
\hline 2 & 34.07 & 0.01 & 22.81 & 34.87 & 3.93 & 3.07 & 1.59 & 0.11 & 100.3 & 0.82 & 0.071 & 0.034 & 0.071 \\
\hline 3 & 35.00 & - & 22.51 & 34.67 & 3.96 & 3.03 & 1.76 & - & 100.9 & 0.81 & 0071 & 0.037 & 0.071 \\
\hline 4 & 34.39 & 0.02 & 22.51 & 33.74 & 3.98 & 3.07 & 1.75 & - & 99.49 & 0.83 & 0.076 & 0.040 & 0.076 \\
\hline 5 & 33.93 & 0.08 & 22.69 & 34.75 & 3.20 & 3.04 & 1.60 & 0.02 & 99.41 & 0.84 & 0.059 & 0.035 & 0.061 \\
\hline 6 & 34.56 & - & 22.58 & 34.26 & 3.96 & 3.09 & 1.89 & 0.02 & 100.3 & 0.81 & 0.072 & 0.041 & 0.072 \\
\hline 7 & 35.77 & - & 22.47 & 34.05 & 3.09 & 3.15 & 1.19 & - & 101.4 & 0.83 & 0.058 & 0.026 & 0.077 \\
\hline 8 & 34.80 & 0.07 & 22.51 & 33.86 & 2.98 & 3.08 & 1.74 & 0.01 & 100.0 & 0.82 & 0.056 & 0.039 & 0.075 \\
\hline 9 & 35.82 & 0.03 & 22.35 & 32.44 & 2.21 & 3.14 & 2.98 & - & 100.0 & 0.81 & 0.042 & 0.068 & 0.078 \\
\hline 10 & 36.61 & 0.09 & 21.79 & 31.99 & 2.28 & 3.22 & 2.04 & 0.12 & 98.14 & 0.82 & 0.045 & 0.048 & 0.080 \\
\hline \multicolumn{14}{|l|}{$\mathrm{Gr}_{3}$} \\
\hline 1 & 35.88 & 0.14 & 22.46 & 30.19 & 1.98 & 6.19 & 1.18 & 0.14 & 99.55 & 0.77 & 0.038 & 0.027 & 0.15 \\
\hline 2 & 35.39 & 0.11 & 22.15 & 35.29 & 2.14 & 5.96 & 1.74 & 0.13 & 100.0 & 0.79 & 0.037 & 0.035 & 0.13 \\
\hline 3 & 35.74 & 0.08 & 22.22 & 35.50 & 2.11 & 5.77 & 1.32 & 0.08 & 100.3 & 0.80 & 0.036 & 0.027 & 0.13 \\
\hline 4 & 35.10 & 0.13 & 22.37 & 34.18 & 2.06 & 5.22 & 1.59 & 0.01 & 100.4 & 0.80 & 0.037 & 0.034 & 0.12 \\
\hline 5 & 34.82 & 0.14 & 21.98 & 32.81 & 2.14 & 5.09 & 1.65 & 0.08 & 98.71 & 0.80 & 0.040 & 0.036 & 0.12 \\
\hline 6 & 33.35 & 0.06 & 21.90 & 33.56 & 2.10 & 4.94 & 1.75 & 0.01 & 99.49 & 0.80 & 0.038 & 0.038 & 0.12 \\
\hline 7 & 34.72 & 0.09 & 22.00 & 32.94 & 2.25 & 4.79 & 1.34 & 0.09 & 100 & 0.81 & 0.042 & 0.030 & 0.12 \\
\hline 8 & 36.85 & 0.13 & 21.39 & 30.42 & 2.32 & 5.53 & 1.51 & 0.09 & 99.31 & 0.77 & 0.047 & 0.035 & 0.14 \\
\hline 9 & 38.33 & 0.13 & 21.29 & 28.94 & 2.17 & 5.71 & 1.87 & 0.13 & 99.79 & 0.75 & 0.049 & 0.044 & 0.15 \\
\hline 10 & 35.87 & 0.17 & 22.13 & 29.38 & 2.01 & 5.99 & 1.09 & 0.09 & 96.83 & 0.77 & 0.042 & 0.026 & 0.15 \\
\hline \multicolumn{14}{|l|}{$\mathrm{Gr}_{4}$} \\
\hline 1 & 35.12 & - & 22.48 & 34.29 & 1.73 & 5.56 & 1.48 & 0.13 & 99.80 & 0.80 & 0.031 & 0.031 & 0.13 \\
\hline 2 & 35.77 & 0.10 & 21.55 & 36.25 & 1.93 & 5.74 & 1.60 & 0.10 & 101.1 & 0.80 & 0.032 & 0.032 & 0.12 \\
\hline 3 & 35.99 & 0.10 & 21.07 & 35.34 & 1.97 & 5.72 & 2.04 & 0.11 & 100.7 & 0.79 & 0.034 & 0.041 & 0.10 \\
\hline 4 & 35.52 & 0.09 & 20.32 & 34.68 & 2.13 & 5.24 & 1.95 & 0.09 & 100.0 & 0.80 & 0.037 & 0.041 & 0.12 \\
\hline 5 & 35.08 & - & 24.57 & 34.48 & 1.86 & 5.32 & 1.88 & - & 100.7 & 0.80 & 0.033 & 0.040 & 0.12 \\
\hline 6 & 35.70 & 0.09 & 22.94 & 33.71 & 1.89 & 5.54 & 1.81 & 0.09 & 100.3 & 0.79 & 0.034 & 0.039 & 0.13 \\
\hline 7 & 35.77 & 0.07 & 22.27 & 34.83 & 1.99 & 5.61 & 2.01 & 0.07 & 99.53 & 0.79 & 0.034 & 0.041 & 0.13 \\
\hline 8 & 36.49 & 0.10 & 22.32 & 33.29 & 2.04 & 6.62 & 2.29 & 0.08 & 100.0 & 0.76 & 0.036 & 0.047 & 0.15 \\
\hline 9 & 36.34 & 0.10 & 21.83 & 32.66 & 2.05 & 6.63 & 1.93 & 0.09 & 99.91 & 0.76 & 0.037 & 0.041 & 0.15 \\
\hline 10 & 37.13 & 0.06 & 21.54 & 31.19 & 2.11 & 5.78 & 1.95 & 0.06 & 99.92 & 0.77 & 0.040 & 0.044 & 0.14 \\
\hline
\end{tabular}

\subsection{Sm-Nd İotop Jeokimyası}

Sm-Nd jeokronolojisi için granat mikaşistlerdeki uniform bileşime sahip granatlar kullanılmıştır (Tablo 2). Jacobsen and Wasserburg (1980)'in model yaş hesaplamalarına göre, analizi yapılan granat örneğinin, çekirdeği ve kenarı arasındaki $\mathrm{Sm} / \mathrm{Nd}$ oranının arasındaki fark azdır. $\mathrm{Bu}$ örneğin çekirdeğinde $82.18 \pm 0.17$, kenarında ise $81.53 \pm 0.10$ yaş verisi elde edilmiştir. Granatın çekirdeği ve kenarından alınan jeokronolojik yaş farkının $(81.53 \pm 0.10$ ve $82.18 \pm 0.17$ ) çok az olması, aynı zamanda hızlı soğumanın mineral üzerindeki etkisinin bir göstergesi olarak kabul edilmiştir (Kaya, 2015). 
Tablo 2. Granat örneğinin Sm-Nd jeokronolojik verisi.

\begin{tabular}{|c|c|c|c|c|c|c|}
\hline Granat minerali & Sm,ppm & Nd,ppm & ${ }^{147} \mathrm{Sm} /{ }^{144} \mathrm{Nd}$ & ${ }^{143} \mathrm{Nd} /{ }^{144} \mathrm{Nd}$ & $+/ 2 \mathrm{~s}$ & Yaş (My) \\
\hline $\begin{array}{l}\text { Granat çekirdeği } \\
\text { ( HD/1) }\end{array}$ & 3.14 & 8.15 & 0.2328 & 0.512058 & 0.000020 & $\begin{array}{c}82.18 \pm \\
0.17\end{array}$ \\
\hline $\begin{array}{l}\text { Granat kenarı } \\
\text { (HD/1) }\end{array}$ & 4.20 & 7.21 & 0.3511 & 0.511958 & 0.000017 & $\begin{array}{c}81.53 \pm \\
0.10\end{array}$ \\
\hline
\end{tabular}

\section{Sonuç ve Tartışma}

Güneydoğu Anadolu Orojenik Kuşağ1 boyunca yüzeylenen ve metamorfik masiflerin en büyüğü olan Pütürge metamorfik masifi (Boray 1975; Helvac1 1983; Göncüoğlu ve Turhan 1984; Genç 1990; Yazgan ve Chessex 1991; Erdem,1994; Ateş,2013) Alpin orojenik kuşağ1 üzerinde yeralmakta olup, magmatik ve sedimanter kökenli değişik kayaçları birarada bulunduran masif özelliğindedir. Genel olarak, yeşilşist ve amfibolit fasiyesi metamorfizma özelliği gösteren bu masifin, metapelitik kayaçları içerisindeki granatların mineralojisi, kimyasal bileşimi, türü, zonlanma özelliği çalışmanın en önemli amacı olup, pütürge metamorfiti granatlarında yapılan Sm-Nd jeokronolojisi çalışmanın diğer bir bölümünü oluşturur. Pütürge masifinde etkili olan Alpin metamorfizması, yay-kıta çarpışması sonucu yitilen kabuk malzemesinin yeşilşist ve amfibolit fasiyesi koşullarında metamorfizma geçirmesine sebep olmuştur. İlk kez Ateş (2013), bu metamorfik masifin psamitlerindeki zirkonlarda U-Pb jeokronolojisi ve metapelitlerindeki amfibollerde ise 40Ar/39Ar jeokronolojik yaş hesaplamasını 84.2, metamorfizma yaşını ise $83.21 \pm 0.069 \mathrm{Ma}$ olarak belirlemiştir. Daha sonra, Kaya (2015) granatlarda Sm-Nd yaşını çekirdekte $82.18 \pm 0.17$ ve granatın kenar kısmında $81.53 \pm 0.10$ olarak belirtmiştir. Araştırmacıların, 40Ar/39Ar ve Sm-Nd jeokronolojik yaş verilerinin birbirine yakın olması elde edilen sonuçların uyumlu olduğunu ve metamorfitlerin metamorfizmaya uğradığı yaş olarak kabul edilecek, bu verilerin Alpin metamorfizmasının yaşı olan Kampaniye işaret ettiği söylenebilir. Jeolojik, petrografik ve mikroskobik çalışmalarda, granatın optik özellikleri ve jeokimyasal sonuçlarla belirlenen kimyasal bileşimleri piralspit ve grandit katı eriyik serisi içerisinde farklı kimyasal bileşime sahip olabilen granatların türünün almandin (Alm81Prp8Grs7Spess5) olduğunu ve dolayısıyla masifin sıcaklığını orta-yüksek sıcaklık seviyelerine eriştiğini verir (Copjakova et al., 2005). Granatların EPMA verilerinin grafikleştirildiği major oksit değişim profilleride, mikroskopik incelemelerle birebir benzer sonuçlar vermektedir. $\mathrm{Bu}$ grafiklerde, major oksit bileşimlerinde belirgin artış veya azalışlar olmamasına rağmen, granatların bazılarında ters zonlanmanın geliştiği ve granatın merkezinden kenarına doğru Mn-değerinde artma ve Fe miktarında ise azalmanın olduğu görülür. $\mathrm{Mg}$ ve Ca-oksit değerlerindeki değişimler ise belirgin değildir. Ters zonlanmanın görüldüğü granat örneklerinde, granatların silimanitle çevrelendiği ve magnezyumun oksit oranındaki değişimin bazı granatlara bitişik biyotit ve klorit minerallerinin varlığından kaynaklandığ ifade edilebilir. Granatların klorit ve silimanit minerallerince çevrelenmiş olması, ayrıca kısmen özşekilli ve düzgün kenarlara sahip kristal özelliği göstermeleri önemlidir. Bu özellik, granatların kenarındaki mangan yüksekliğinin katyon alış-veriş reaksiyonlarının sonucu gelişebileceğinin işaretidir (Dietvorst, 1980). Petrografik, mineralojik, kimyasal ve izotop veriler 
birlikte değerlendirildiğinde, metamorfitlerin bölgesel metamorfizmanın Amfibolit fasiyesi Stavrolit zonunda ilerleyen ve Yeşilşist fasiyesinde gerileyen türden iki metamorfizma geçirdiği ve bölgedeki neotektonik olayların masifin metamorfizmasına yakından etki ettiği, ayrıca tektonizmanın metamorfitlerin yüzeye çıkma sürecinde hem gerileyen (retrograde) metamorfizmaya, hemde hızlı soğumaya neden olduğu söylenebilir. Metamorfitlerin hesaplanan sıcaklığı ise yaklaşık $628^{\circ} \mathrm{C}$ civarında olduğu çalışmanın hesaplamalarla ulaştığı diğer bir sonuçtur.

\section{Teşekkür}

$\mathrm{Bu}$ çalışma, Fırat Üniversitesi Bilimsel Araştırma Projeleri (FÜBAP) Birimi tarafindan, Fübap-MF-12.42 no'lu proje kapsamında desteklenmiş ve projelendirilmiştir. Mali kaynak sağlayan, üniversitemiz FÜBAP birimine teşekkür ederiz.

\section{Kaynaklar}

Ateş, C. 2013 Metamorfik kayaçlardaki zirkon mineralinin kristal yapısı ve metamorfizma koșullarının etkisi. Pütürge Metamorfiti Örneği, Yüksek Lisans Tezi, Fırat Universitesi, Elazı $\breve{g}$ $1-88$.

Atherton, M.P. 1968. The variation in garnet, biotite, and chlorite composition in medium grade pelitic rocks from the Dalradian, Scotland, with particular reference to the zonation in garnet. Contributions to Mineralogy and Petrologoy, 18, 347-371.

Boray, A. 1975. Bitlis dolayının yapısı ve metamorfizması. Türkiye Jeoloji Bülteni, 18, 81-84.

Carlson, W.D. 1989. The significance of intergranular diffusion to the mechanisms and kinetics of porphyroblast crystallization. Contributions to Mineralogy and Petrology, 103, 1-24.

Copjakova, R., Sulovsky, P., Paterson, B.A. 2005. Major and trace elements in pyrope-almandine garnets as sediment provenance indicators of the Lower Carboniferous Culm sediments, Drahany Uplands. Bohemian Massif, Lithos, 82, 51-70.

Christensen, J.N., Rosenfeld, J., DePaolo, D. 1989. Rates of tectonometamorphic processes from rubidium and strontium isotopes in garnet. Science, 244, 14651469.

Cygan, R.T., Lasaga, A.C. 1985. Selfdiffusion of magnesium in garnet at $750^{\circ} \mathrm{C}$ to $900^{\circ} \mathrm{C}$. American Journal of Science, 285, 328 - 350 .

Dietvorst, E.J.L. 1980. Biotite breakdown and the formation of gahnite in metapelitic rocks from Kemio, Southwest Finland. Contributions to Mineralogy and Petrology, 75, 327337.

Erdem, E. 1994 Pütürge (Malatya) metamorfitlerinin petrografik ve petrolojik özellikleri. Doktora Tezi, Frrat Üniversitesi Fen Bilimleri Enstitüsü, Elazı̆ğ,1-119.

Erkan, Y. 2013. Metamorfik Petrografi. Hacettepe Üniversitesi yayını, Ankara, 1-154.

Frost, M.J. 1962. Metamorphic grade and iron-magnesium distribution between coexisting garnet-biotite and garnethornblende. Geological Magazine, 99, 427-38.

Genç, S. 1990. Bitlis masifi, ÇökekyazıGökay (Hizan, Bitlis) yöresi metamorfitlerinin petrografisi, metamorfizması ve kökeni, Türkiye Jeoloji Bülteni, 33, 1-14.

Göncüoğlu, M.C., Turhan, N. 1984. Geology of the Bitlis metamorfik belt. International Symposium on the Geology of the Taurus Belt, Ankara, 237-244.

Helvac1, C., Griffin, W.L. 1984. Rb-Sr geochronology of the Bitlis massif, Avnik (Bingöl) area, SE Turkey. In: Dixon, J.E. and Robertson, A.H.F. (eds). Geological Evolution of the Eastern Mediterranean. Special 
Publication of the Geological Society of London, 17, 403-413.

Hollister, L.S. 1966. Garnet zoning: an interpretation based on the Rayleigh fractionation model. Science, 154, 1647-1651.

Jacobsen S.B., Wasserburg G. J. 1980. Sm$\mathrm{Nd}$ evolution of chondrites. Earth Planetary Science Letters, 50, 139- 155.

Kaya, H. 2015 Pütürge Metamorfitinde Yitim Zonu Metamorfizmasının Petrolojik Modellemesi. Yüksek Lisans Tezi, Frrat Universitesi Fen Bilimleri Enstitüsü, Elazı̆̆ , 1-109.

Kretz, R. 1973. Kinetics of the crystallization of garnet at two localities near Yellow knife. Canadian Mineralogist, 12, 1-20.

Kılıç, A.D., Kaya H. 2015. Pütürge metamorfitlerindeki zonlu granatların incelenmesi. Firat Universitesi Bilimsel Araştırma Projesi (MF 12.42), 1-105.

Kılıç, A.D., Ateş, C. 2014. Metamict zircon and Structural Characters: Pütürge Metamorphite Example. Turkish Journal of Science \& Technology, 9 (2), 127-133.

Kılıç, A.D., Ateş, C. 2015. Geochronology of the Late Cretaceous magmatism and metamorphism, Pütürge massif. Turkey, Acta Petrologica Sinica, 31 (5).

Lasaga, A.C, Richardson S.M., Holland, H. D. 1977. The mathematics of cation diffusion and exchange between silicate minerals during retrograde metamorphism, In: Saxena SK, Bhattacharji S (eds) Energetics of geological processes. Springer, New York, pp 353- 388.

Miyashiro, A. 1972. Metamorphism and Metamorphic Belts. George Allen \& Unwin, London, 1-492.

Michard, A., Whitechurch, H., Ricou, I.E., Montigny, R., Yazgan, E. 1984. Tauric subduction (Malatya-Elazığ provinces) and its bearing on tectonics of the Tethyan realm in Turkey. In: Dixon, J.E. and Robertson, A.H.F. (eds). Geological Evolution of the Eastern Mediterranean. Special Publication of the Geological Society of London, 17, 361-374.

Perinçek, D., Özkaya, İ. 1981. Tectonic evolution of the northern margin of Arabian plate. Yerbilimleri, 8, 91-101.

Ramberg, H., 1952. The origin of metamorphic and metasomatic rocks. Chicago: Chicago Universal Press.

Ricou, L.E., Marcoux, J., Whitechurch, H. 1984. The Mesozoic organization of the Taurides: one or several oceanic basins. In: Dixon, J.E., Robertson, A.H.F. (eds.). The Geological Evolution of the Eastern Mediterranean. Special Publication of the Geological Society of London, 17, 349-360.

Robertson, A.H.F., Dixon, J.E. 1984. Introduction aspects of the geological evolution of the Eastern Mediterranian. Special Publication of the Geological Society of London, london, 17, 1-74.

Ruiz, L.P. 1976. The zoning of garnets as an indicator of the P.T. history of their host-rocks. Annales de la Societe Geologique de Belgique, 99, 337-346.

Şengör, A.M.C., Y1lmaz, Y. 1981. Tethyan evolution of Turkey: A plate tectonic approach. Tectonophyscis, 75, 181241.

Tracy, R.J., Robinson, P. 1976. Garnet composition and zoning in the determination of temperature and pressure of metamorphism, central Massachussetts. American Mineralogist, 61, 762-775.

Williams, M.L., Grambling, J.A. 1990. Manganese,ferric iron, and the equilibrium between garnet and biotite. American Mineralogist, 75, 886-908.

Yardley, B.W.D. 1989. An Introduction to Metamorphic Petrology. Longman Scientific and Technical, New York, 1248.

Yazgan, E., Chessex, R. 1991. Geology and tectonic evolution of the southestern Taurides in the region of Malatya. Turkiye Petrol Jeologları Dergisi, 3 (1), $1-41$. 